Check for updates

Cite this: Nanoscale Adv., 2019, 1, 2240

\section{Ionic liquids to monitor the nano-structuration and the surface functionalization of material electrodes: a proof of concept applied to cobalt oxyhydroxide $\uparrow$}

\author{
Jacob Olchowka, (D) *ab Tiphaine Tailliez, ${ }^{\text {a }}$ Lydie Bourgeois, ${ }^{c}$ Marie Anne Dourges ${ }^{c}$ \\ and Liliane Guerlou-Demourgues (D) *ab
}

\begin{abstract}
This paper reports on an innovative and efficient approach based on the use of ionic liquids to govern the nano-structuration of $\mathrm{HCOO}_{2}$, in order to optimize the porosity and enhance the ionic diffusion through the electrode materials. In this work, we show that (1-pentyl-3-methyl-imidazolium bromide (PMIMBr) and 1-ethyl-3-methylimidazolium tetrafluoroborate $\left(\mathrm{EMIMBF}_{4}\right)$ ) ionic liquids (ILs) used as templates during the synthesis orientate the nanoparticle aggregation which leads to increase of the porosity and the average pore size of the electrode material. It is also demonstrated that the ILs are strongly bonded to the $\mathrm{HCOO}_{2}$ surface, leading to surface functionalized $\mathrm{HCoO}_{2}$ materials, also called nanohybrids. This surface tailoring stabilizes the material upon cycling and shifts the oxidation potential linked to the Co(III)/ Co(iv) redox couple to lower voltage in an alkaline $5 \mathrm{M} \mathrm{KOH}$ electrolyte. The surface and porosity optimizations facilitate the ionic diffusion through the material, improve the electron transfer ability within the electrode and lead to greatly enhanced specific capacity in both alkaline $5 \mathrm{M}-\mathrm{KOH}$ and neutral $0.5 \mathrm{M}^{-} \mathrm{K}_{2} \mathrm{SO}_{4}$ aqueous electrolytes $\left(66.7 \mathrm{~mA} \mathrm{~h} \mathrm{~g}^{-1}\right.$ and $47.5 \mathrm{~mA} \mathrm{~h} \mathrm{~g}^{-1}$ respectively for $\mathrm{HCOO}_{2}-\mathrm{PMIMBr}$ and $\mathrm{HCOO}_{2}-\mathrm{EMIMBF}_{4}$ compared to $18.1 \mathrm{~mA} \mathrm{~h} \mathrm{~g}^{-1}$ for bare $\mathrm{HCoO}_{2}$ in $5 \mathrm{M}-\mathrm{KOH}$ at $1 \mathrm{~A} \mathrm{~g}^{-1}$ ).
\end{abstract}

Received 19th March 2019 Accepted 9th April 2019

DOI: 10.1039/c9na00171a

rsc.li/nanoscale-advances carbon electrodes thanks to the fast and reversible redox processes occurring at the material surface, and on battery-like faradaic electrodes for hybrid supercapacitor systems.9-11 Several metal oxides/(oxy)hydroxides such as $\mathrm{RuO}_{2}, \mathrm{MnO}_{2}$, $\mathrm{Co}(\mathrm{OH})_{2}, \mathrm{Ni}(\mathrm{OH})_{2}, \mathrm{Co}_{3} \mathrm{O}_{4}, \mathrm{HCoO}_{2}$, and $\mathrm{NiCoO}_{2}$ have been widely investigated and show promising features. ${ }^{12-21}$ However, for all of them, nano-structuration to optimize the electrode-electrolyte interface and a conductive scaffold to improve their electronic conductivity are crucial for maximizing their performances. ${ }^{22-24}$ Among all these electrode materials, non-stoichiometric layered cobalt oxyhydroxide $\left(\mathrm{HCoO}_{2}\right)$ offers a two dimensional structure suitable for fast ionic diffusion as well as a good intrinsic electronic conductivity due the high oxidation state of cobalt, which favors electron transportation. ${ }^{25,26}$ While the $\mathrm{HCoO}_{2}$ pristine material usually exhibits a specific capacitance between 130 and $140 \mathrm{~F} \mathrm{~g}^{-1}$ in $\mathrm{KOH}$ electrolytes at $1 \mathrm{~A}$ $\mathrm{g}^{-1}, 27,28$ different strategies were investigated to improve its electrochemical performances. For example, C. J. Raj et al. focused on nano-structuration by developing a hydrothermal synthesis to get $\mathrm{HCoO}_{2}$ nanorods with a specific capacitance of $177 \mathrm{~F} \mathrm{~g}^{-1}$ at $5 \mathrm{mV} \mathrm{s}^{-1},{ }^{29}$ whereas $\mathrm{Zhu}$ et al. developed $\mathrm{HCoO}_{2} /$ CNT (carbon nanotube) hybrids ${ }^{27,30}$ giving $270 \mathrm{~F} \mathrm{~g}^{-1}$ and $312 \mathrm{~F}$ $\mathrm{g}^{-1}$ at $1 \mathrm{~A} \mathrm{~g}^{-1}$. Other groups prepared $\mathrm{HCoO}_{2}$ thin films, ${ }^{31-33}$ or MWCNT/CoOOH multilayer films, ${ }^{34}$ via synthesis strategies for which they claim an improved specific capacitance (up to $463 \mathrm{~F}$

${ }^{a}$ CNRS, Univ. Bordeaux, Bordeaux INP, ICMCB UMR 5026, F-33600 Pessac, France. E-mail: jacob.olchowka@icmcb.cnrs.fr

${ }^{b} R S 2 E$, Réseau Français sur le Stockage Electrochimique de l'Energie, FR CNRS 3459, F80039 Amiens Cedex 1, France

'Institut des Sciences Molaires, Univ. Bordeaux, UMR 5255, F-33405 Talence, France

$\dagger$ Electronic supplementary information (ESI) available. See DOI: 10.1039/c9na00171a 
$\mathrm{g}^{-1}$ at $1.8 \mathrm{~A} \mathrm{~g}^{-1}$ (ref. 31)), but the mass loading of the active material is usually very limited by this technique. More recently, Zhang et al. reported a method to grow ultrathin $\mathrm{HCoO}_{2}$ nanoflakes on nickel foam, exhibiting a surprisingly very high specific capacitance of $2550 \mathrm{~F} \mathrm{~g}^{-1}$ at $1.25 \mathrm{~A} \mathrm{~g}^{-1}$ in $\mathrm{KOH}$, which demonstrates that developing nano-structuration strategies is essential to improve the electrochemical performances. ${ }^{25}$ It should be noted that these capacity values were often obtained in alkaline media, in which the charge storage processes are mainly faradaic, leading in most cases to non-rectangular curve shapes in cyclic voltammetry, so that expressing the capacitances in $\mathrm{F} \mathrm{g}^{-1}$ is usually not relevant, and should be replaced by capacities in $\mathrm{C}$ or $\mathrm{mA} \mathrm{h} \mathrm{g}^{-1}$. Nevertheless, these capacity values are often not mentioned in the publications, which is the reason why, for the sake of convenience, only capacitance values in $\mathrm{F} \mathrm{g}^{-1}$ are reported in this introduction.

Ionothermal synthesis which is still poorly used for energy storage material synthesis could perfectly fulfil the nano-structuration criterion..$^{35-37}$ The ionic liquids (IL) used as (co)solvent are also able to play the key role of surfactants and/or structure directing agents allowing us to tailor the size, the shape and the agglomeration/porosity of the synthesized inorganic nanomaterials and hybrid nanomaterials. ${ }^{38-44}$ In fact, ILs can form extended hydrogen-bond systems in the liquid state to be highly structured, which can serve as the "entropic driver" for spontaneous, well-defined, and extended ordering of nanoscale structures. Thus, synthesis in ionic liquids allows a better control on the nanostructuration of the materials (particles size, porosity, and pore size) than simple hybridization, where an inorganic material is impregnated on a conductive carbonbased material (graphene and carbon nanotubes). Moreover, during the synthesis, the ILs can be strongly bonded to the inorganic material surface to modify material characteristics such as the solubility, stability, chemical reactivity or energy transfer properties. ${ }^{36,39,45-49}$ For instance, B. G. Choi et al. synthesized a $\mathrm{BMIMBF}_{4}-\mathrm{Co}(\mathrm{OH})_{2}$ hybrid electrode material and have shown by DFT calculations that ILs tethered to the $\mathrm{Co}(\mathrm{OH})_{2}$ surface allow faster proton adsorption/desorption processes, which contribute to lowering the energy barrier of the pseudo-capacitive process, thus improving the electrochemical performances. ${ }^{46}$

In this work, we report on two IL-cobalt oxyhydroxide nanohybrid materials prepared by a precipitation method. The two imidazolium based ionic liquids, 1-pentyl-3-methyl-imidazolium bromide (PMIMBr) and 1-ethyl-3-methylimidazolium tetrafluoroborate $\left(\mathrm{EMIMBF}_{4}\right)$, were chosen for (i) their availability compared to some other ionic liquids, (ii) their high intrinsic ionic conductivity, (iii) their hydrophilic character and (iv) their ability to be used as a structure directing agent ${ }^{50-53}$ and also because imidazolium has the ability to adsorb on the material surface, to functionalize the inorganic material and to facilitate $\mathrm{H}^{+}$adsorption. ${ }^{46}$ We investigate in the present work the influence of the ionic liquid on the nano-structuration (porosity, pore size, and aggregation) of the nanomaterial and correlate it to the electrochemical performances. The materials have been tested in both $\mathrm{KOH}$ and $\mathrm{K}_{2} \mathrm{SO}_{4}$ aqueous electrolytes. The basic medium leads to "bulk" faradaic reactions inducing the best performances in terms of capacity and allows comparing our material to the literature. On the other hand, the "bulk" faradaic reactions are strongly limited in $\mathrm{K}_{2} \mathrm{SO}_{4}$ electrolyte, in which the behavior is expected to be more pseudocapacitive. Finally, beyond the important improvement of $\mathrm{HCoO}_{2}$ capacity, ionic conductivity and stability, we believe that this material design approach (nano-structuration and surface functionalization by ILs) is a proof of concept and can be transposed to other materials.

\section{Experimental}

The synthesis of beta-3 cobalt oxyhydroxide (named $\mathrm{HCoO}_{2}$ ) consists of a precipitation in an alkaline oxidizing medium starting from Co(II) solution. First, $3.18 \mathrm{~g}$ of $\mathrm{Co}\left(\mathrm{NO}_{3}\right)_{2} \cdot 6 \mathrm{H}_{2} \mathrm{O}\left(10^{-2}\right.$ $\mathrm{mol}$ ) are dissolved in $300 \mathrm{~mL}$ of water. Then $11 \mathrm{~mL}$ of $\mathrm{NaOH}(2 \mathrm{M})$ are added dropwise to the solution under stirring. After some seconds, the unstable blue precipitate corresponding to alpha$\mathrm{Co}(\mathrm{OH})_{2} \cdot x \mathrm{H}_{2} \mathrm{O}$ formed because the sodium hydroxide addition turns pink and leads to the formation of beta- $\mathrm{Co}(\mathrm{OH})_{2}$. Afterwards, $7.5 \mathrm{~mL}$ of $\mathrm{NaClO}\left(48^{\circ} \mathrm{Cl}\right)$ are added dropwise to the solution in order to speed up the oxidation process leading to the oxyhydroxide phase. The solution is stirred overnight, centrifuged 6 times in water for $3 \mathrm{~min}$ at $4000 \mathrm{rpm}$ and dried $24 \mathrm{~h}$ at $50{ }^{\circ} \mathrm{C}$. The synthesis procedure for $\mathrm{HCoO}_{2}-\mathrm{PMIMBr}$ and $\mathrm{HCoO}_{2}-$ EMIMBF$_{4}$ is the same, except that $3 \mathrm{~mL}$ of 1-pentyl-3-methylimidazolium bromide (PMIMBr) and $3 \mathrm{~mL}$ of 1-ethyl-3-methylimidazolium tetrafluoroborate $\left(\mathrm{EMIMBF}_{4}\right)$ are added respectively to the starting solution of water.

$\mathrm{X}$-ray diffraction (XRD) data for each material were collected with a Philips PANalytical X'Pert Pro diffractometer using cobalt $\mathrm{K} \alpha$ radiation $(1.789 \AA)$. The diffraction patterns were recorded for around 25 hours (1800.48 s per step) in the $10-110^{\circ}(2 \theta)$ angular range, with a $0.0167^{\circ}(2 \theta)$ step size and a $2.122^{\circ}(2 \theta)$ active width in the detector.

Infrared spectroscopy measurements were performed on $\mathrm{HCoO}_{2}$-type materials using a FTIR Nicolet 6700 (Thermo Scientific) equipped with a diffuse reflectance accessory, suitable for studying powders and rough surfaces. Each sample was mixed with dried $\mathrm{KBr}$ - transparent in the middle IR range (400$4000 \mathrm{~cm}^{-1}$ ) - and finely ground (the mass ratio between each material and $\mathrm{KBr}$ being approximately $1: 10)$. Reflectance spectra were treated with the Kubelka-Munk law, which converts the reflectance to a signal proportional to the absorption coefficient. Infrared spectroscopy measurements were performed on ionic liquids using a FTIR Nicolet iS50 (Thermo Scientific) equipped with an attenuated total reflectance accessory (ATR) which requires no specific sample preparation. A single reflection system with a diamond crystal was used to analyse the sample. All the results obtained on powders were also confirmed by ATR.

Specific surface area determination and mesoporosity assessment were performed by recording nitrogen sorption isotherms with a Micromeritics ASAP2010 equipment (Micromeritics Corp., Norcross, GA, USA) after degassing each sample at $100{ }^{\circ} \mathrm{C}$ in a vacuum for a time interval long enough to reach a constant pressure $(<10 \mu \mathrm{m} \mathrm{Hg})$. The nitrogen adsorption- 
desorption isotherms were measured at liquid nitrogen temperature $(77 \mathrm{~K})$ with $P / P_{0}$ ranging from 0 to 0.99 . The BET equation was then applied between 0.01 and 0.3 relative pressure $\left(P / P_{0}\right)$ to calculate the specific surface areas (named BETSA). ${ }^{54}$ Pore size distributions were evaluated by using the Barrett, Joyner, Halenda $(\mathrm{BJH})$ model applied to the desorption branch of the isotherms. ${ }^{55}$ TGA measurements were performed on a SDT Q600 V3.8 Build 51 instrument under an air flow of $100 \mathrm{~mL} \min ^{-1}$ between room temperature and $700{ }^{\circ} \mathrm{C}$.

\section{Electrode preparation}

Electrochemical measurements were performed in both aqueous $5 \mathrm{M}-\mathrm{KOH}$ and $0.5 \mathrm{M}-\mathrm{K}_{2} \mathrm{SO}_{4}$ electrolytes in a three electrode mode at room temperature. Platinum wire was used as the counter electrode in both cases, whereas $\mathrm{Hg} / \mathrm{HgO}$ was used as the reference electrode in a basic electrolyte and $\mathrm{Ag} /$ $\mathrm{AgCl}$ in $0.5 \mathrm{M}-\mathrm{K}_{2} \mathrm{SO}_{4}$. The working electrode was prepared with a mixture of active material/carbon black/polytetrafluoroethylene in a weight ratio of 80/15/5. A disk of about $6 \mathrm{~mm}$ diameter of the electrode material, with a weight of $\sim 5 \mathrm{mg}$, was pressed for $30 \mathrm{~s}$ at 6 bar on nickel foam (current collector) for testing in $\mathrm{KOH}$ and on a stainless steel sheet for testing in $\mathrm{K}_{2} \mathrm{SO}_{4}$. This results in a $7 \mathrm{~mm}$ disk and hence an active material loading of $\sim 10.4 \mathrm{mg} \mathrm{cm} \mathrm{cm}^{-2}$. The three electrodes (working electrode, reference electrode and counter electrode) were placed in the electrolyte in order to form an equilateral triangle and each electrode was separated from the other two by $\approx 16$ $\mathrm{mm}$. Electrochemical impedance measurements were performed under open-circuit conditions. A small AC perturbation amplitude of $10 \mathrm{mV}$ versus the open-circuit potential was applied in a frequency range from $50 \mathrm{kHz}$ down to $0.1 \mathrm{~Hz}$. Cyclic Voltammetry (CV), Constant Current Charge/Discharge (CCCD) and Electrochemical Impedance Spectroscopy (EIS) were performed using an EC-lab potentiostat. The nickel foam alone was tested in $5 \mathrm{M} \mathrm{KOH}$ as the electrode material and the results have shown that it exhibits a negligible contribution to capacity.

\section{Results and discussion}

XRD patterns presented in Fig. 1 confirm that all three syntheses lead to the formation of the rhombohedral- $\mathrm{HCoO}_{2}$ phase. The reported line indexation is performed with a hexagonal cell, with $3 \mathrm{CoO}_{2}$ slabs per cell (space group: $R \overline{3} m, a=2.851$ $\AA$ and $c=13.150 \AA$ ). The addition of an ionic liquid during the synthesis did not lead to additional reflection peaks or any significant change in the XRD pattern, contrary to what was reported by Choi et al. for $\mathrm{IL}-\mathrm{Co}(\mathrm{OH})_{2}$, where an additional broad reflection peak was observed compared to bare $\mathrm{Co}(\mathrm{OH})_{2} \cdot{ }^{46}$ Moreover, the absence of shift of the (003) reflection, the interreticular distance of which corresponds to the interslab space, suggests that no additional species coming from the ionic liquid is inserted within the interslab space. ${ }^{\mathbf{5 6}}$

On the other hand, some differences could be observed in the aggregation of the particles. Scanning electron microscopy (SEM) images (Fig. 2) show that the $\mathrm{HCoO}_{2}$ nanoplatelets tend to produce bigger agglomerates when the ionic liquid is

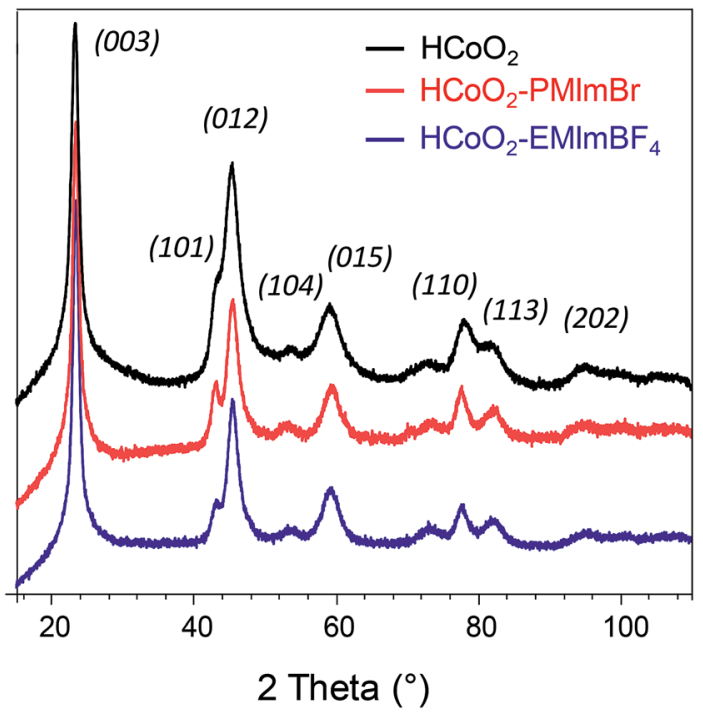

Fig. 1 X-ray diffraction patterns of $\mathrm{HCoO}_{2}$ (black) (reference card 01072-2280), $\mathrm{HCOO}_{2}-\mathrm{PMIMBr}$ (red) and $\mathrm{HCOO}_{2}-\mathrm{EMIMBF}_{4}$ (blue)

introduced during the synthesis. This effect seems to be more pronounced for $\mathrm{HCoO}_{2}-\mathrm{PMIMBr}$ and surprisingly, for this material, the primary particles tend to aggregate to form thick layers with a plane surface whereas the surface of the agglomerate looks less regular for $\mathrm{HCoO}_{2}-\mathrm{EMIMBF}_{4}$ and jagged for bare $\mathrm{HCoO}_{2}$. This tendency is confirmed when increasing the resolution. The surface of bare $\mathrm{HCoO}_{2}$ exhibits nanoplatelets stacked on their edge whereas they are piled up randomly in the presence of ionic liquids. For all materials, the length of the nanoplatelets is similar, ranging from 60 to $100 \mathrm{~nm}$.

Fig. 3 shows the $\mathrm{N}_{2}$ adsorption/desorption isotherms as well as pore size distribution of the reference $\mathrm{HCoO}_{2}$ and the two $\mathrm{HCoO}_{2}-\mathrm{EMIMBF}_{4}$ and $\mathrm{HCoO}_{2}-\mathrm{PMIMBr}$ nanomaterials. Although the aggregation is different between the three materials, they all present a type IV isotherm including a hysteresis loop that indicates the existence of large mesopores and comparable adsorption surface areas. The BET surface area (BET-SA) increases by about $10 \%$ for $\mathrm{HCoO}_{2}-\mathrm{PMIMBr}$ (BET-SA = $\left.135 \mathrm{~m}^{2} \mathrm{~g}^{-1}\right)$ compared to bare $\mathrm{HCoO}_{2}\left(\right.$ BET-SA $\left.=122 \mathrm{~m}^{2} \mathrm{~g}^{-1}\right)$ and decreases by about $15 \%$ for the other nano-hybrid $\mathrm{HCoO}_{2}^{-}$ EMIMBF$_{4}\left(\right.$ BET-SA $\left.=104 \mathrm{~m}^{2} \mathrm{~g}^{-1}\right)$. On the other hand, the distribution of pore volume differs. For $\mathrm{HCoO}_{2}$, a main part of the porosity comes from small mesopores with a diameter around $4 \mathrm{~nm}$, the second population centered at $15 \mathrm{~nm}$ is less significant and a BJH desorption average pore diameter of 6.97 $\mathrm{nm}$ is calculated. Concerning the two nanohybrids, the mesopore population with a diameter of $4 \mathrm{~nm}$ is still present, but in minority compared to bigger mesopores (population with a diameter of $\sim 7 \mathrm{~nm}$ and $\sim 15 \mathrm{~nm}$ for $\mathrm{HCoO}_{2}-\mathrm{EMIMBF}_{4}$ and a diameter of $\sim 7 \mathrm{~nm}$ and $\sim 13 \mathrm{~nm}$ for $\left.\mathrm{HCoO}_{2}-\mathrm{PMIMBr}\right)$. This leads to a $\mathrm{BJH}$ desorption average pore diameter of $8.34 \mathrm{~nm}$ and $9.77 \mathrm{~nm}$ for $\mathrm{HCoO}_{2}-\mathrm{EMIMBF}_{4}$ and $\mathrm{HCoO}_{2}-\mathrm{PMIMBr}$ respectively. Therefore, the $\mathrm{BJH}$ desorption cumulative volume of pores increases for the two nanohybrids $\left(0.29 \mathrm{~cm}^{3} \mathrm{~g}^{-1}\right.$ for $\mathrm{HCoO}_{2}-\mathrm{EMIMBF}_{4}$ and $0.34 \mathrm{~cm}^{3} \mathrm{~g}^{-1}$ for $\mathrm{HCoO}_{2}-\mathrm{PMIMBr}$ ) 

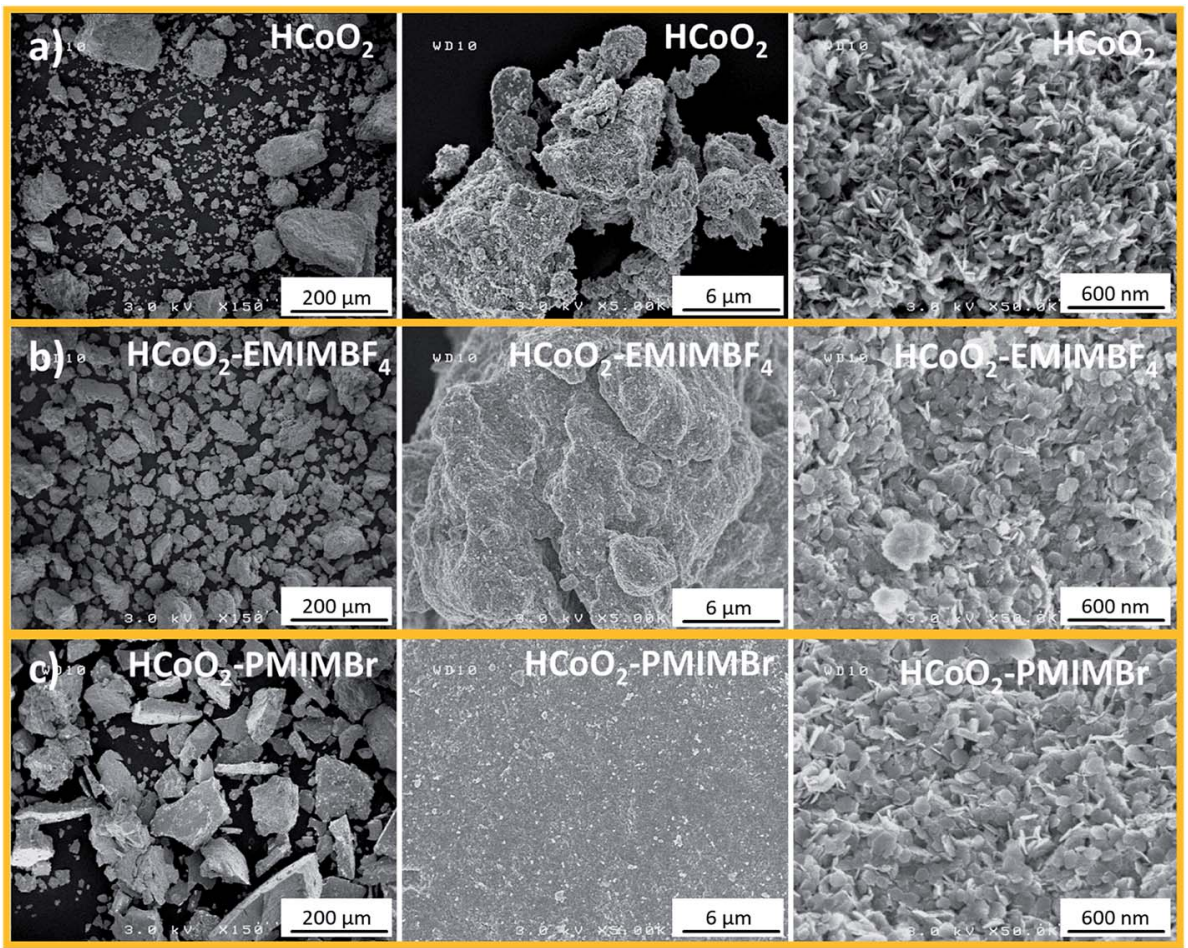

Fig. 2 Scanning electron microscopy images of (a) $\mathrm{HCOO}_{2}$, (b) $\mathrm{HCOO}_{2}-\mathrm{EMIMBF}_{4}$ and (c) $\mathrm{HCOO}_{2}-\mathrm{PMIMBr}$.

compared to reference $\mathrm{HCoO}_{2}\left(0.24 \mathrm{~cm}^{3} \mathrm{~g}^{-1}\right)$, which reveals a higher porosity for the materials synthesized in the presence of ionic liquids.

ILs are well known for their ability to adsorb on the surface of nanomaterials and to influence material morphology and aggregation due to their steric hindrance effect and in this case, to increase the porosity and the pore size average. ${ }^{43,57,58}$ Imidazolium based ionic liquids are especially used in material synthesis since they can form hydrogen bonds with the electronegative element of the material surface and generate $\pi-\pi$ stacking in the liquid phase to design structured materials. ${ }^{57,59}$ The formation mechanism proposed in our case is based on this last approach. For both $\mathrm{HCoO}_{2}-\mathrm{EMIMBF}_{4}$ and $\mathrm{HCoO}_{2}-$ PMIMBr, the positively charged cations 1-ethyl-3-methylimidazolium and 1-pentyl-3-methylimidazolium can easily be adsorbed on the oxygen surface of the layered cobalt oxyhydroxide by electrostatic forces, leading to a hydrogen bond formed between the proton on the $\mathrm{C} 2$ position of the imidazolium ring (proton between the two nitrogen) and the surface oxygen (see ESI S1 $\dagger$ ). The proton in the $\mathrm{C} 2$ position is considered because of its higher Lewis acidity compared to the others. ${ }^{60}$ The generated $\pi-\pi$ interactions between imidazole rings orient the adsorbed ionic liquid molecules parallel to each other and stabilize the functionalized nanomaterial. The selforganization of the two nanohybrid structures is confirmed by FTIR analyses and SEM-EDX. Fig. 4 showing the SEM-EDX elemental mappings demonstrates the presence of ionic liquid homogeneously distributed over the final nanohybrid materials. Atoms from the anionic part of the ionic liquid, "F" and "Br" for $\mathrm{EMIMBF}_{4}$ and $\mathrm{PMIMBr}$ respectively, were chosen as a reference for the mapping since a carbon film was used as a support. Quantitative analyses give a weight ratio of $\sim 0.7 \mathrm{wt} \%$ for fluoride and $\sim 1 \mathrm{wt} \%$ for bromide, which shows that ionic liquids are present in a low concentration, in good agreement with surface functionalization. These results are supported by thermogravimetric analysis (see ESI S2 $\dagger$ ) which shows a weight loss of $21 \%$ at $700{ }^{\circ} \mathrm{C}$ for the two nanohybrids versus $20 \%$ for reference $\mathrm{HCoO}_{2}$.

The surface functionalization is also clearly demonstrated by FTIR spectra, as shown in Fig. 5. For $\mathrm{HCoO}_{2}-\mathrm{EMIMBF}_{4}$, the two bands at 3110 and $3149 \mathrm{~cm}^{-1}$ that are assigned to the $\mathrm{C}-\mathrm{H}$ stretching modes $\left(\nu_{\mathrm{C}-\mathrm{H}}\right)$ of the imidazolium ring are shifted to lower wavenumbers compared to the pure ionic liquid. This phenomenon suggests that strong interactions are involved between the ionic liquid and the surface of the inorganic material and can be attributed to both the hydrogen bonding between the acidic proton of the imidazolium ring and the oxygen surface of $\mathrm{HCoO}_{2}$ and to the $\pi-\pi$ stack interactions of the aligned imidazolium rings which decrease the electronic density of $\mathrm{C}-\mathrm{H}$ bonds of the ring and thus, weaken their bond strength. ${ }^{61}$ The $\nu_{\mathrm{C}-\mathrm{H}}$ mode of the aliphatic chain observed below $3050 \mathrm{~cm}^{-1}$ (ethyl and methyl) is also found to be influenced. New signals appear at $2839 \mathrm{~cm}^{-1}$ and $3030 \mathrm{~cm}^{-1}$, and existing bands gain in intensity. In this case, the mutual packing of positively charged imidazolium could influence the nitrogenalkyl carbon bonds, changing the $\nu_{\mathrm{C}-\mathrm{H}}$ modes. ${ }^{61}$

For $\mathrm{HCoO}_{2}-\mathrm{PMIMBr}$, the $\nu_{\mathrm{C}-\mathrm{H}}$ bands of the imidazolium ring are located at higher wavenumbers than those of the pure ionic liquid (3110 and $3147 \mathrm{~cm}^{-1}$ for $\mathrm{HCoO}_{2}-\mathrm{PMIMBr}$ compared to 3055 and $3138 \mathrm{~cm}^{-1}$ for PMIMBr). This phenomenon can be 
a)

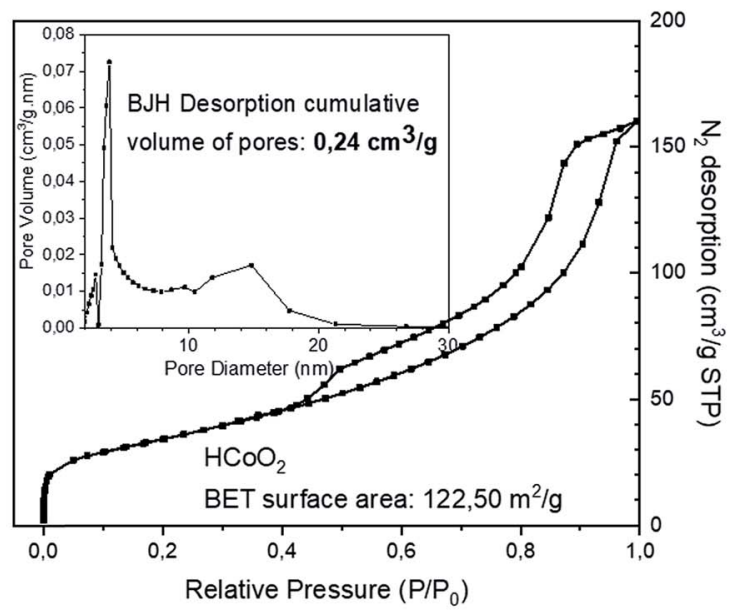

c)

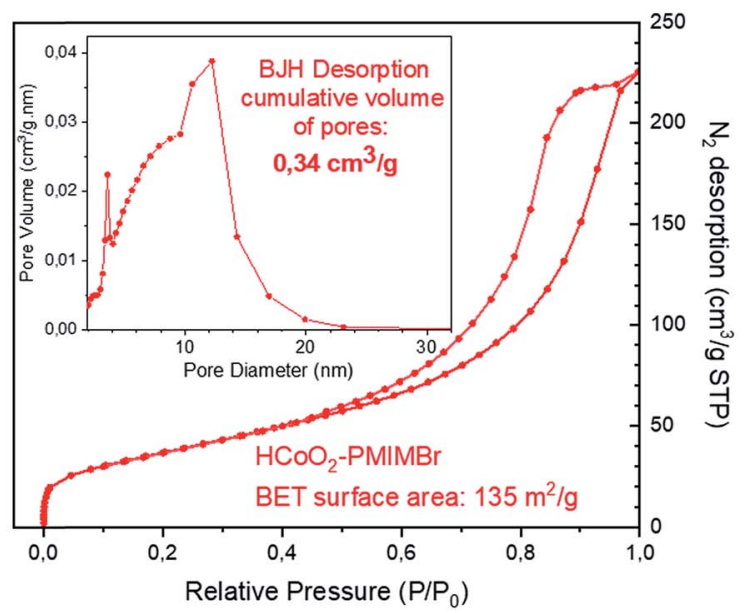

b)

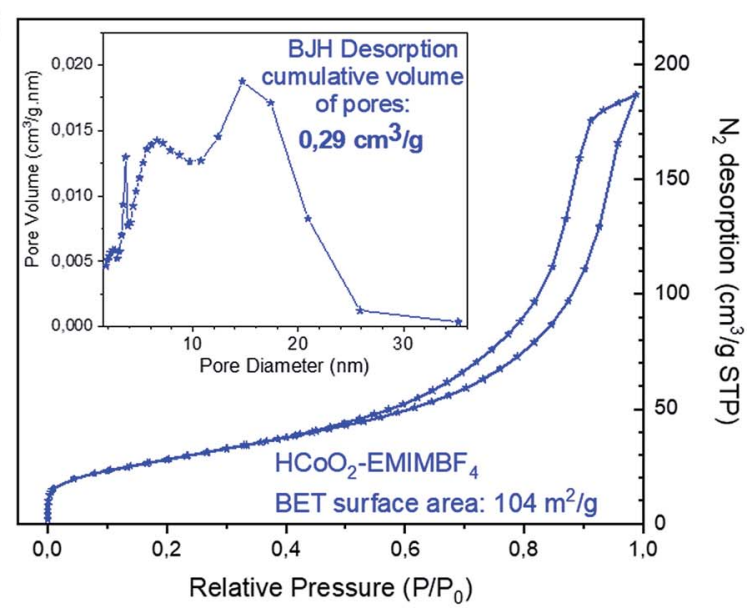

Fig. $3 \mathrm{~N}_{2}$ adsorption/desorption isotherms as well as pore size distribution of (a) $\mathrm{HCOO}_{2}$ (b) $\mathrm{HCoO}_{2}-\mathrm{EMIMBF}_{4}$ and (c) $\mathrm{HCOO}_{2}-\mathrm{PMIMBr}$.

explained by the fact that upon surface adsorption and $\pi-\pi$ stack interactions of imidazolium rings, the initial strong hydrogen bond between acidic hydrogen of the imidazolium ring and the bromide is weakened or broken, leading to a relocalization of bromide anions. These observations are in good agreement with the report of Cha et al. which shows a stronger interaction between halides and hydrogen of the imidazolium ring than between $\mathrm{BF}_{4}{ }^{-}$and the same hydrogen. ${ }^{62}$ Moreover, they also observed a similar continuous shift to higher wavenumbers when increasing the amount of diluted water in BMIMBr. ${ }^{62}$ In an analogous manner, the bands below $3000 \mathrm{~cm}^{-1}$ assigned to $\nu_{\mathrm{C}-\mathrm{H}}$ vibrations of the aliphatic chain
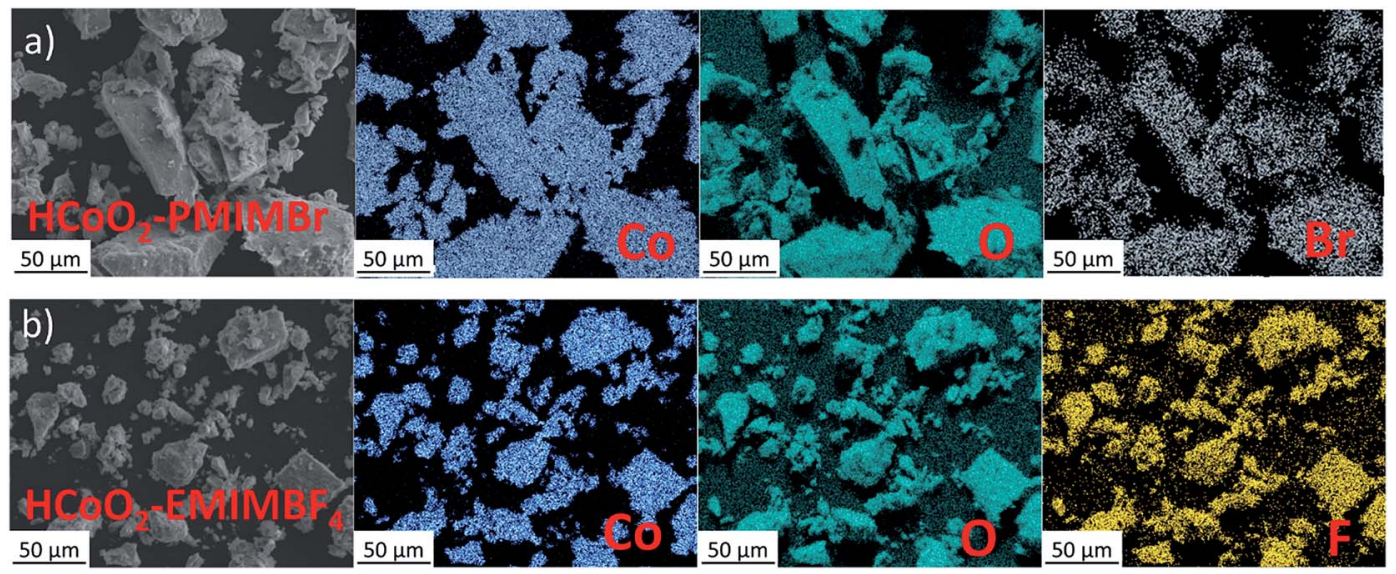

Fig. 4 Energy dispersive X-ray (EDX) mapping analysis for the two nanohybrids, (a) $\mathrm{HCoO}_{2}-\mathrm{PMIMBr}$ and (b) $\mathrm{HCoO}_{2}-\mathrm{EMIMBF}_{4}$. 


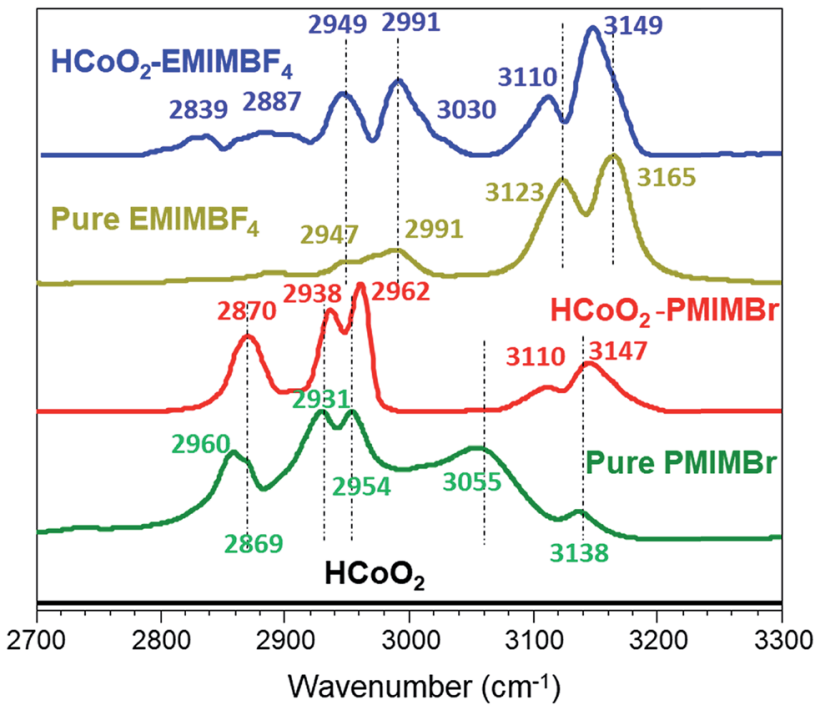

Fig. 5 Infrared spectra of the nanohybrids and pure ionic liquids: comparison of $\nu_{\mathrm{C}-\mathrm{H}}$ bands. shift to higher energies compared to pure PMIMBr. Hence, on the basis of the infrared data, it can be assumed that the ionic liquids are grafted to the surface of cobalt oxyhydroxide.

One could also notice that the $\nu_{\mathrm{C}-\mathrm{H}}$ bands of imidazolium rings are centered at very similar wavenumbers for the two nanohybrids $\left(3110\right.$ and $3149 \mathrm{~cm}^{-1}$ for $\mathrm{HCoO}_{2}-\mathrm{EMIMBF}_{4}$ and 3110 and $3147 \mathrm{~cm}^{-1}$ for $\mathrm{HCoO}_{2}-\mathrm{PMIMBr}$ ) although they are quite different in the pure ionic liquids (see Fig. 5). They are also very close to those reported in the literature where the $\pi-\pi$ stack interactions of imidazolium based nanohybrids were observed (3103 and $3149 \mathrm{~cm}^{-1}$ for $\mathrm{Co}(\mathrm{OH})_{2}-\mathrm{BMIMBF}_{4}, 3093$ and $3151 \mathrm{~cm}^{-1}$ for $\mathrm{Fe}_{2} \mathrm{O}_{3}-\mathrm{BMIMCl}$ and 3099 and $3152 \mathrm{~cm}^{-1}$ for $\left.\mathrm{TiO}_{2}-\mathrm{EMIMBr}\right) .{ }^{\mathbf{4 6 , 5 9 , 6 0}}$

\section{Electrochemical performances}

The electrochemical energy storage properties of the two nanohybrids were investigated by cyclic voltammetry (CV) and galvanostatic charge/discharge (GCD) in neutral $\left(0.5 \mathrm{M}-\mathrm{K}_{2} \mathrm{SO}_{4}\right)$ and basic $(5 \mathrm{M}-\mathrm{KOH})$ aqueous media and were compared to those of reference $\mathrm{HCoO}_{2}$. The $\mathrm{CV}$ curves measured at $5 \mathrm{mV} \mathrm{s}^{-1}$ a)

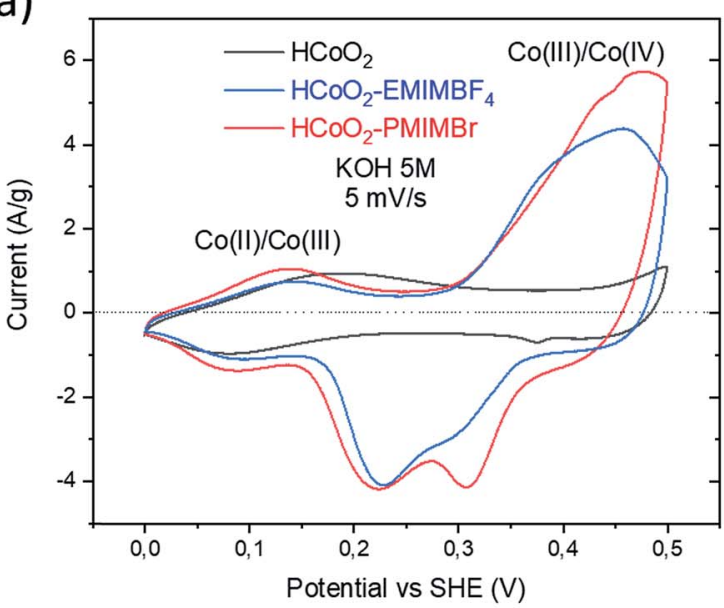

c)

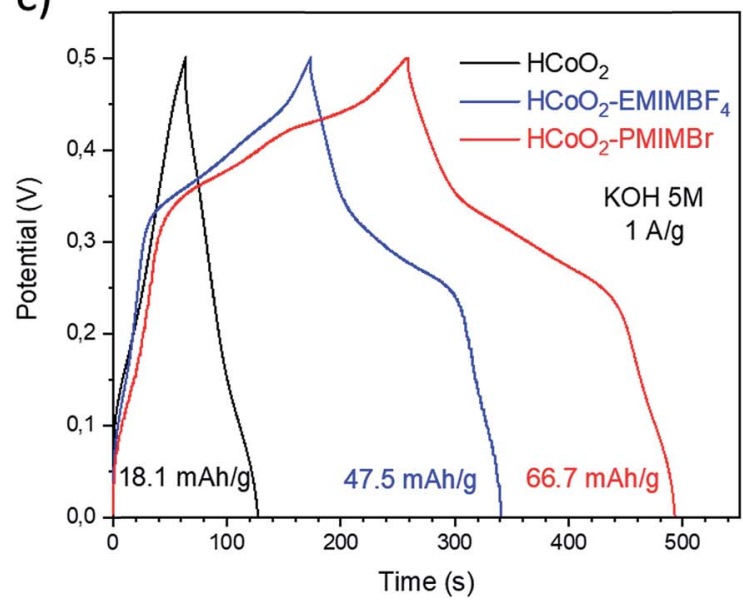

b)

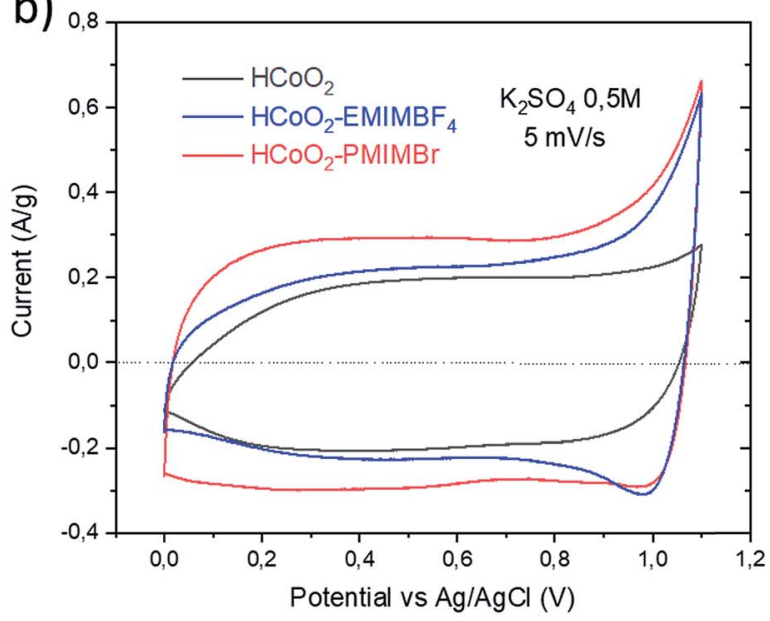

d)

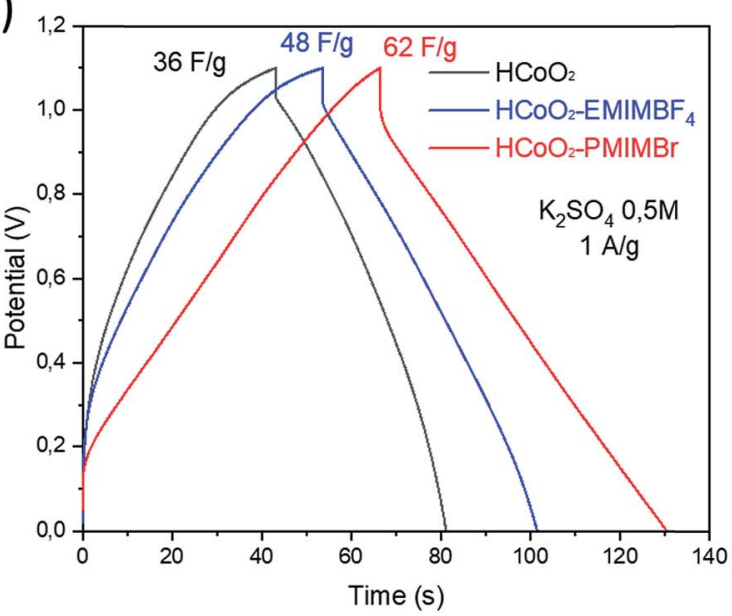

Fig. 6 Cycling voltammetry curves of $\mathrm{HCOO}_{2}, \mathrm{HCOO}_{2}-\mathrm{EMIMBF}_{4}$ and $\mathrm{HCOO}_{2}-\mathrm{PMIMBr}$ electrodes at $5 \mathrm{mV} \mathrm{s}{ }^{-1}$ in a (a) $5 \mathrm{M}-\mathrm{KOH}$ electrolyte and

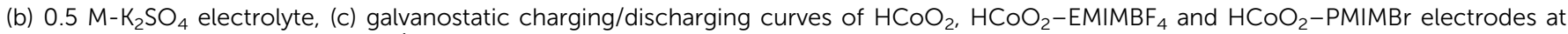
a constant current density of $1 \mathrm{~A} \mathrm{~g}^{-1}$ in a $5 \mathrm{M}-\mathrm{KOH}$ electrolyte and (d) in a $0.5 \mathrm{M}-\mathrm{K}_{2} \mathrm{SO}_{4}$ electrolyte. 
in $5 \mathrm{M}-\mathrm{KOH}$ present rather symmetric shapes suggesting high reversibility of faradaic reactions (Fig. 6a). For both nanohybrids, the curves reveal two main redox peaks during the oxidation processes, the first one at $0.014 \mathrm{~V}$ and the second at 0.46-0.47 V which may respectively be assigned to the $\mathrm{Co}(\mathrm{II}) /$ $\mathrm{Co}(\mathrm{III})$ and $\mathrm{Co}(\mathrm{III}) / \mathrm{Co}(\mathrm{Iv})$ redox processes. ${ }^{25,27}$ These peaks are displaced to lower potential compared to bare $\mathrm{HCoO}_{2}$ for which the first peak is at $0.19 \mathrm{~V}$ and the second at $0.52 \mathrm{~V}$ (see ESI S3 $\dagger$ ). ${ }^{26}$ These displacements of redox potentials, most probably caused by the surface modification by the ionic liquids, allow shifting the $\mathrm{Co}(\mathrm{III}) / \mathrm{Co}(\mathrm{Iv})$ oxidation potential inside the electrochemical windows of $5 \mathrm{M}-\mathrm{KOH}$, leading to a higher peak current and higher charge capacity. It is quite reasonable to suppose that the ionic liquids grafted on the surface facilitate the insertion/ deinsertion of the cations present in the electrolyte, which lowers the oxidation potential. Fig. 6c represents the galvanostatic charge-discharge profiles in a $5 \mathrm{M}-\mathrm{KOH}$ electrolyte, measured at $1 \mathrm{~A} \mathrm{~g}^{-1}$ for the three different electrode materials. The specific capacity evaluated from the discharged curves is clearly enhanced for the two nanohybrids, $47.5 \mathrm{~mA} \mathrm{~h} \mathrm{~g}^{-1}(342 \mathrm{~F}$ $\left.\mathrm{g}^{-1}\right)$ for $\mathrm{HCoO}_{2}-\mathrm{EMIMBF}_{4}$ and $66.7 \mathrm{~mA} \mathrm{~h} \mathrm{~g}{ }^{-1}\left(480 \mathrm{~F} \mathrm{~g}^{-1}\right)$ for $\mathrm{HCoO}_{2}-\mathrm{PMIMBr}$, compared to the $18.1 \mathrm{~mA} \mathrm{~h} \mathrm{~g}^{-1}\left(130 \mathrm{~F} \mathrm{~g}^{-1}\right)$ for $\mathrm{HCoO}_{2}$. The capacity observed for $\mathrm{HCoO}_{2}-\mathrm{PMIMBr}$ is higher than most of those reported in the literature for nanostructured $\mathrm{HCoO}_{2}$ and $\mathrm{HCoO}_{2}$ hybridized with a conductive carbon material. ${ }^{27-30,32-34,63}$ These results confirm the efficiency of the presented nano-structuration approach. Moreover, as shown in Fig. 7, these electrodes show an excellent cycling stability and a good coulombic efficiency over 1000 cycles. In a $0.5 \mathrm{M}-\mathrm{K}_{2} \mathrm{SO}_{4}$ electrolyte, the CV curves, represented in Fig. 6b, exhibit a rectangular shape characteristic of pseudocapacitive behavior. This proves that the energy storage behavior of an electrode strongly depends on the nature of the electrolyte, and the basic electrolyte favors faradaic reactions i.e. bulk proton intercalation/deintercalation compared to the $\mathrm{K}_{2} \mathrm{SO}_{4}$ one. ${ }^{64}$ In the neutral electrolyte, the pseudocapacitive behavior of the three electrode materials is also confirmed by galvanostatic charge-discharged (GCD) measurements (Fig. 6d) in which a nearly linear dependence of potential with time can be observed. ${ }^{65}$ Once again, the presence of an ionic liquid functionalizing the surface nanomaterial enhances the specific capacitance $\left(36 \mathrm{~F} \mathrm{~g}^{-1}, 48 \mathrm{~F} \mathrm{~g}^{-1}\right.$ and $62 \mathrm{~F} \mathrm{~g}^{-1}$ for $\mathrm{HCoO}_{2}$, $\mathrm{HCoO}_{2}-\mathrm{EMIMBF}_{4}, \mathrm{HCoO}_{2}-\mathrm{PMIMBr}$ respectively). In a $\mathrm{K}_{2} \mathrm{SO}_{4}$ electrolyte, it can be assumed that most of the capacitance comes from electrode surface reactions (adsorption and surface redox reactions) due to the rectangular shape of $\mathrm{CV}$ curves. In spite of this last point, we could not establish direct correlation between the measured BET surface area $\left(122 \mathrm{~m}^{2}\right.$ $\mathrm{g}^{-1}$ for $\mathrm{HCoO}_{2}, 104 \mathrm{~m}^{2} \mathrm{~g}^{-1}$ for $\mathrm{HCoO}_{2}-\mathrm{EMIMBF}_{4}$, and $135 \mathrm{~m}^{2}$ $\mathrm{g}^{-1}$ for $\mathrm{HCoO}_{2}-\mathrm{PMIMBr}$ ) and the specific capacitance (which is much better for the nanohybrids). On the other hand, it can be noted that increasing the porosity of the material $\left(0.24 \mathrm{~cm}^{3}\right.$ $\mathrm{g}^{-1}, 0.29 \mathrm{~cm}^{3} \mathrm{~g}^{-1}$ and $0.34 \mathrm{~cm}^{3} \mathrm{~g}^{-1}$ respectively for $\mathrm{HCoO}_{2}$, $\mathrm{HCoO}_{2}-\mathrm{EMIMBF}_{4}$ and $\mathrm{HCoO}_{2}-\mathrm{PMIMBr}$ ), which may improve accessibility to the active sites, enhances the energy storage capacity of the nanomaterials (see Fig. 3). Nevertheless, these results demonstrate that, for pseudocapacitive materials, the

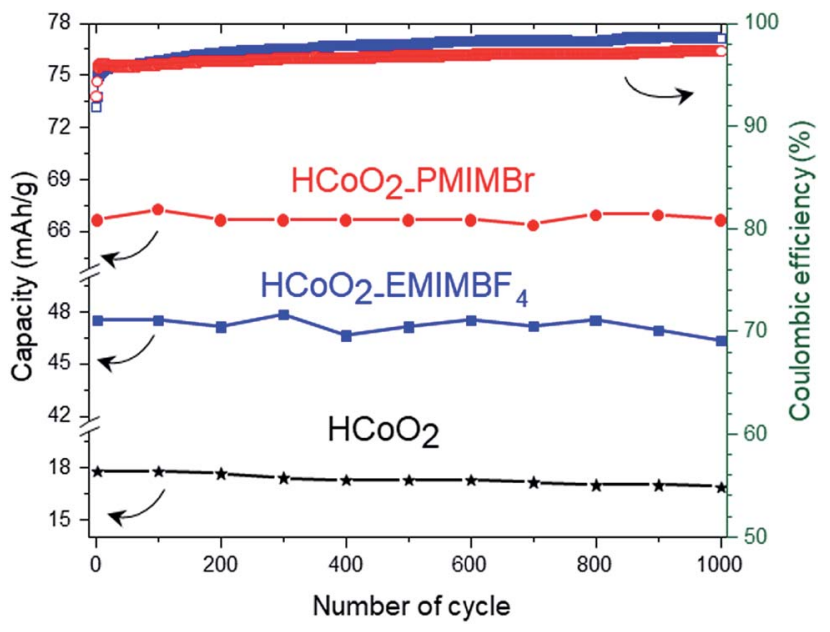

Fig. 7 Variation of specific capacity over 1000 cycles for $\mathrm{HCOO}_{2}$, $\mathrm{HCOO}_{2}-\mathrm{EMIMBF}_{4}$, and $\mathrm{HCOO}_{2}-\mathrm{PMIMBr}$ electrodes at a constant current density of $1 \mathrm{~A} \mathrm{~g}^{-1}$ in $5 \mathrm{M}-\mathrm{KOH}$ and evolution of the coulombic efficiency.

BET surface area cannot be directly linked to the capacitance performance and that the nature of the ionic liquid used during the synthesis strongly influences the electrochemical performances.

To study the effect of $\mathrm{HCoO}_{2}$ surface modification on conductivity properties, electrochemical impedance spectroscopy (EIS) analyses were performed in both $\mathrm{K}_{2} \mathrm{SO}_{4}$ and $\mathrm{KOH}$ electrolytes. The Nyquist plot of $\mathrm{HCoO}_{2}, \mathrm{HCoO}_{2}-$ $\mathrm{EMIMBF}_{4}$ and $\mathrm{HCoO}_{2}-\mathrm{PMIMBr}$ in the $\mathrm{K}_{2} \mathrm{SO}_{4}$ electrolyte, shown in Fig. 8b, is composed of a semi-circle in the highfrequency region and a linear part in the low frequency one. The charge transfer resistance $\left(R_{\mathrm{CT}}\right)$ calculated using the same equivalent circuit as that of Justin Raj et al. (see ESI S4 $\dagger$ ) is much smaller for the nanohybrid materials $\left(R_{\mathrm{CT}}=5.6 \Omega\right.$ and $R_{\mathrm{CT}}=5.7 \Omega$ for $\mathrm{HCoO}_{2}-\mathrm{EMIMBF}_{4}$ and $\mathrm{HCoO}_{2}-\mathrm{PMIMBr}$ respectively) than for the bare material $\left(R_{\mathrm{CT}}=17.8 \Omega\right) .{ }^{29}$ Furthermore, the most vertical line in the low-frequency region for the functionalized material and especially for $\mathrm{HCoO}_{2}-\mathrm{EMIMBF}_{4}$ also implies a better ionic diffusion through the electrode. The bigger average pore volume diameter for $\mathrm{HCoO}_{2}-\mathrm{EMIMBF}_{4}$ is most probably a key parameter that explains the better ionic diffusion. Finally, one of the direct consequences of the better interfacial charge transfer and ionic diffusion is the enhanced performance at a high cycling rate (see Fig. $8 \mathrm{~d}$ and ESI S5 $\dagger$ ). $\mathrm{HCoO}_{2}$ $\mathrm{EMIMBF}_{4}$, which shows the best ionic conductivity, exhibits also the best capacity retention when increasing the cycling rate (e.g. $49 \%$ capacity retention at $200 \mathrm{mV} \mathrm{s}^{-1}$ compared to $5 \mathrm{mV} \mathrm{s}^{-1}$ against only $17 \%$ for $\mathrm{HCoO}_{2}$ and $36 \%$ for $\mathrm{HCoO}_{2}-$ PMIMBr).

Similar interpretation can be made in a $5 \mathrm{M}-\mathrm{KOH}$ electrolyte; $\mathrm{HCoO}_{2}-\mathrm{EMIMBF}_{4}$ shows a lower charge transfer resistance as well as the best capacity retention at a high cycling rate (see Fig. 8a and c), whereas both $\mathrm{HCoO}_{2}-\mathrm{EMIMBF}_{4}$ and $\mathrm{HCoO}_{2}-$ PMIMBr present a much better ionic conductivity (more vertical line in the low frequency range) than bare $\mathrm{HCoO}_{2}$. 
a)

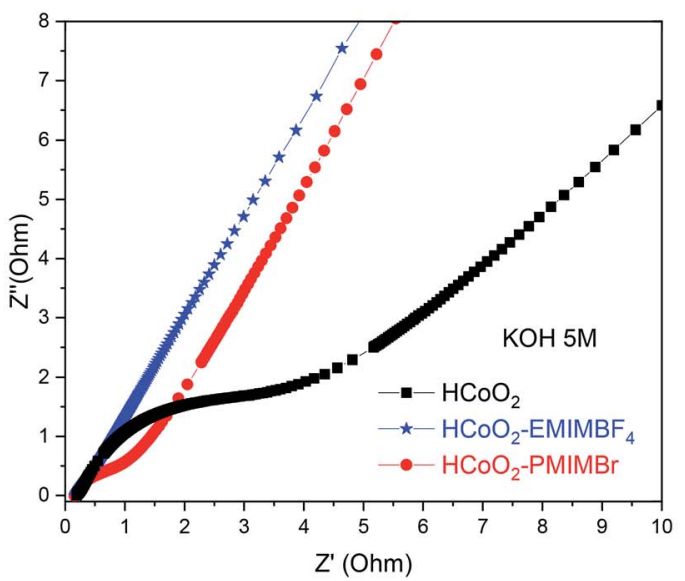

c)

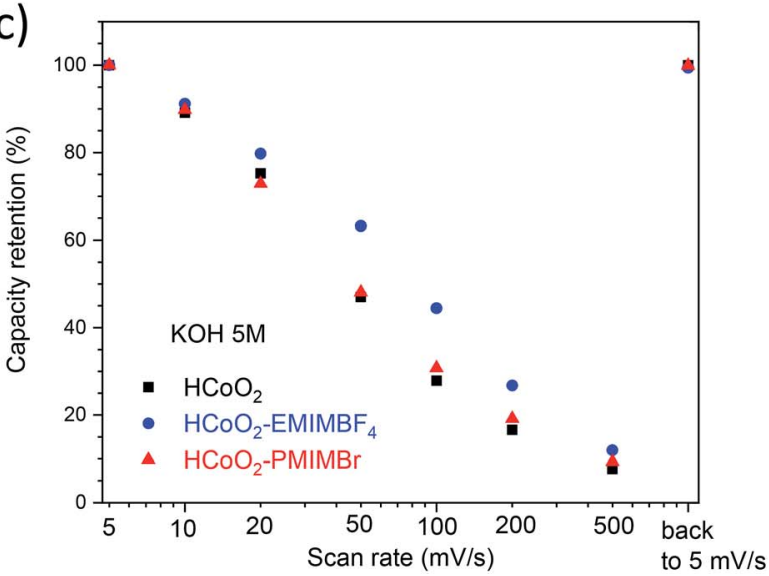

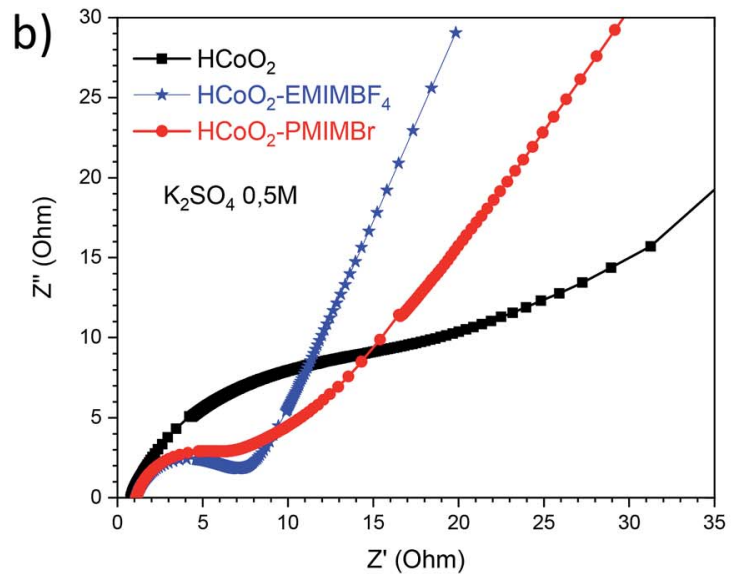

d)

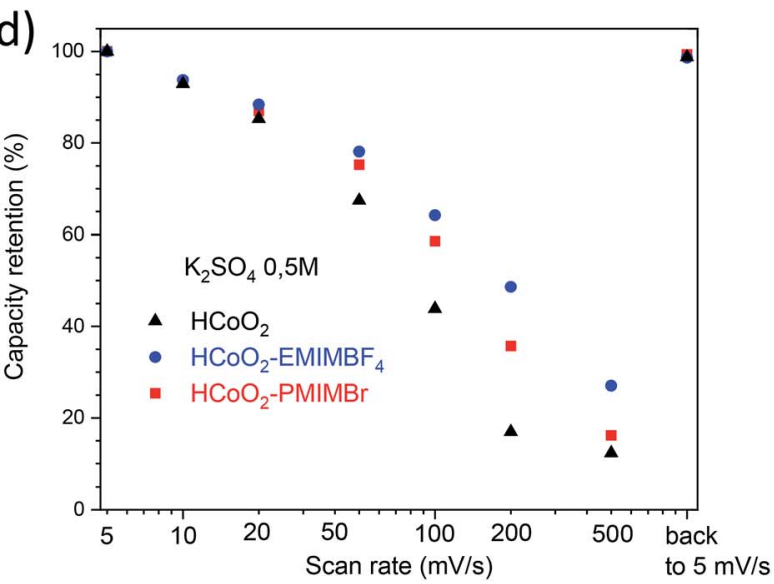

Fig. 8 Nyquist plot of $\mathrm{HCOO}_{2}, \mathrm{HCOO}_{2}-\mathrm{EMIMBF}_{4}$ and $\mathrm{HCOO}_{2}-\mathrm{PMIMBr}$ electrodes measured in a (a) $5 \mathrm{M}-\mathrm{KOH}$ electrolyte and (b) $0.5 \mathrm{M}-\mathrm{K}_{2} \mathrm{SO}_{4}$ electrolyte, (c) capacity retention in a high cycling range compared to the capacity measured at $5 \mathrm{mV} \mathrm{s}^{-1}$ in a $5 \mathrm{M}-\mathrm{KOH}$ electrolyte and (d) in a 0.5 $\mathrm{M}-\mathrm{K}_{2} \mathrm{SO}_{4}$ electrolyte.

\section{Conclusion}

This work shows that the synthesis of ionic liquid-based nanohybrids can be a way to develop new electrode materials with optimized electrochemical energy storage performances. During the synthesis of cobalt oxyhydroxide, ionic liquids are used both as templates to tailor the nano-structuration, leading to the generation of mesopores and facilitating the ionic diffusion, and also as reactants to functionalize the $\mathrm{HCoO}_{2}$ surface. This functionalization, demonstrated by SEM-EDX analyses and by FTIR measurements, lowers the $\mathrm{Co}^{3+} / \mathrm{Co}^{4+}$ oxidation potential and shifts it from the OER region towards the electrochemical stability window of a $5 \mathrm{M} \mathrm{KOH}$ electrolyte. Both the bare $\mathrm{HCoO}_{2}$ and the functionalized $\mathrm{HCoO}_{2}$ electrodes show rather pseudocapacitive behavior in neutral $\mathrm{K}_{2} \mathrm{SO}_{4}$ whereas faradaic reactions are enhanced in the $5 \mathrm{M}-\mathrm{KOH}$ electrolyte. Compared to the reference $\mathrm{HCoO}_{2}$, the specific capacity of $\mathrm{HCoO}_{2}-\mathrm{PMIMBr}$ has been multiplied by $\sim 3.7$ in alkaline electrolytes and the specific capacitance has strongly increased in the neutral medium $\left(66.7 \mathrm{~mA} \mathrm{~h} \mathrm{~g}^{-1}\right.$ and $62 \mathrm{~F} \mathrm{~g}^{-1}$ respectively in $5 \mathrm{M}-\mathrm{KOH}$ and $0.5 \mathrm{~K}_{2} \mathrm{SO}_{4}$ versus $18.1 \mathrm{~mA} \mathrm{~h} \mathrm{~g}{ }^{-1}$ and $36 \mathrm{~F} \mathrm{~g}^{-1}$ ). Additionally, it is shown that the nature of the ionic liquid has a significant impact on the electrode performances. We consider this work as a proof of concept, which can be applied to other electrode materials.

\section{Conflicts of interest}

There are no conflicts to declare.

\section{Acknowledgements}

The authors would like to thank Philippe Dagault for thermogravimetry measurements and Catherine Denage for Scanning Electron Microscopy Imaging. The authors also thank the French National Research Agency (STORE-EX Labex Project ANR-10-LABX-76-01 for funding.

\section{References}

1 N. Choudhary, C. Li, J. Moore, N. Nagaiah, L. Zhai, Y. Jung and J. Thomas, Adv. Mater., 2017, 29, 1605336.

2 M. Salanne, B. Rotenberg, K. Naoi, K. Kaneko, P. L. Taberna, C. P. Grey, B. Dunn and P. Simon, Nat. Energy, 2016, 1, 16070. 3 J. R. Miller and P. Simon, Science, 2008, 321, 651-652. 
4 Y. Wang, J. Guo, T. Wang, J. Shao, D. Wang and Y.-W. Yang, Nanomaterials, 2015, 5, 1667-1689.

5 P. Simon and Y. Gogotsi, Nat. Mater., 2008, 7, 845-854.

6 C. Bodin, E. Mourad, D. Zigah, S. Le Vot, S. A. Freunberger, F. Favier and O. Fontaine, Faraday Discuss., 2017, 1-12.

7 H. Liu, Y. Zhang, Q. Ke, K. H. Ho, Y. Hu and J. Wang, J. Mater. Chem. A, 2013, 1, 12962-12970.

8 Z. Peng, Z. Guo, W. Chu and M. Wei, RSC Adv., 2016, 6, 42019-42028.

9 V. Augustyn, J. Come, M. A. Lowe, J. W. Kim, P. L. Taberna, S. H. Tolbert, H. D. Abruña, P. Simon and B. Dunn, Nat. Mater., 2013, 12, 518-522.

10 A. González, E. Goikolea, J. Andoni and R. Mysyk, Renewable Sustainable Energy Rev., 2016, 58, 1189-1206.

11 V. Augustyn, P. Simon and B. Dunn, Energy Environ. Sci., 2014, 7, 1597.

12 M. Toupin, T. Brousse and D. Bélanger, Chem. Mater., 2004, 16, 3184-3190.

13 G. Godillot, H. Huo, M. Ménétrier, L. Bourgeois, L. GuerlouDemourgues and C. Delmas, J. Phys. Chem. C, 2012, 116, 26598-26607.

14 A. Adán-más, R. G. Duarte, T. M. Silva, L. Guerloudemourgues, M. Fátima and G. Montemor, Electrochim. Acta, 2017, 240, 323-340.

15 G. Godillot, P.-L. Taberna, B. Daffos, P. Simon, C. Delmas and L. Guerlou-Demourgues, J. Electrochem. Soc., 2016, 163, A2004-A2010.

16 X. Ge, C. D. Gu, Y. Lu, X. L. Wang and J. P. Tu, J. Mater. Chem. A, 2013, 1, 13454.

17 C. Julien and A. Mauger, Nanomaterials, 2017, 7, 396.

18 X. Wang, W. Li, X. Wang, J. Zhang, L. Sun, C. Gao, J. Shang, Y. Hu and Q. Zhu, RSC Adv., 2017, 7, 50753-50759.

19 H. Xia, Y. Shirley Meng, G. Yuan, C. Cui and L. Lu, Electrochem. Solid-State Lett., 2012, 15, A60.

20 E. Eustache, C. Douard, R. Retoux, C. Lethien and T. Brousse, Adv. Energy Mater., 2015, 5, 3-7.

21 X. Pétrissans, A. Bétard, D. Giaume, P. Barboux, B. Dunn, L. Sicard and J. Y. Piquemal, Electrochim. Acta, 2012, 66, 306-312.

22 W. Wei, X. Cui and D. G. Ivey, Chem. Soc. Rev., 2011, 40, 1697-1721.

23 B. Mei, B. Li, J. Lin and L. Pilon, J. Electrochem. Soc., 2017, 164, A3237-A3252.

24 B. Dong, M. Li, S. Chen, D. Ding, W. Wei, G. Gao and S. Ding, ACS Appl. Mater. Interfaces, 2017, 9, 17890-17896.

25 D. Zhang, X. Kong, Y. Zhao, M. Jiang and X. Lei, J. Mater. Chem. A, 2016, 4, 12833-12840.

26 K. K. Lee, W. S. Chin and C. H. Sow, J. Mater. Chem. A, 2014, 2, 17212-17248.

27 L. Zhu, W. Wu, X. Wang, X. Wu, W. Tang and Y. Wu, RSC Adv., 2014, 4, 59088-59093.

28 W. Wen, D. Liang, J. P. Cheng and J. M. Wu, RSC Adv., 2016, 6, 70947-70951.

29 C. Justin Raj, B. C. Kim, W. J. Cho, S. Park, H. T. Jeong, K. Yoo and K. H. Yu, J. Electroanal. Chem., 2015, 747, 130135.
30 L. Zhu, W. Wu, Y. Zhu, W. Tang and Y. Wu, J. Phys. Chem. C, 2015, 119, 7069-7075.

31 M. Wang, W. Ren and Y. Zhao, Renewable Sustainable Energy Rev., 2014, 16, 2181.

32 A. D. Jagadale, D. P. Dubal and C. D. Lokhande, Mater. Res. Bull., 2012, 47, 672-676.

33 D. S. Dhawale, S. Kim, D. H. Park, J. H. Choy, S. S. Al-deyab, K. Ariga, E. Kim and A. Vinu, ChemElectroChem, 2015, 2, 497502.

34 H. Zheng, F. Tang, M. Lim, T. Rufford, A. Mukherji, L. Wang and G. Lu, J. Power Sources, 2009, 193, 930-934.

35 D. R. MacFarlane, M. Forsyth, P. C. Howlett, M. Kar, S. Passerini, J. M. Pringle, H. Ohno, M. Watanabe, F. Yan, W. Zheng, S. Zhang and J. Zhang, Nat. Rev. Mater., 2016, 1, 15005.

36 G. G. Eshetu, M. Armand, B. Scrosati and S. Passerini, Angew. Chem., Int. Ed., 2014, 53, 13342-13359.

37 K. Qi and W. Zheng, Current Opinion in Green and Sustainable Chemistry, 2017, 5, 17-23.

38 J. Olchowka, M. Suta and C. Wickleder, Chem.-Eur. J., 2017, 23, 12092-12095.

39 H. Terraschke, J. Olchowka, E. Geringer, A. V. Rodrigues and C. Wickleder, Small, 2018, 14, 1703707.

40 X. Kang, X. Sun, X. Ma, P. Zhang, Z. Zhang, Q. Meng and B. Han, Angew. Chem., Int. Ed., 2017, 56, 12683-12686.

41 R. E. Morris, Chem. Commun., 2009, 2990.

42 D. Freudenmann, S. Wolf, M. Wolff and C. Feldmann, Angew. Chem., Int. Ed., 2011, 50, 11050-11060.

43 M. Antonietti, D. Kuang, B. Smarsly and Y. Zhou, Angew. Chem., Int. Ed., 2004, 43, 4988-4992.

44 B. G. Bharate, P. E. Hande, A. B. Samui and P. S. Kulkarni, Renewable Energy, 2018, 126, 437-444.

45 S. S. Moganty, N. Jayaprakash, J. L. Nugent, J. Shen and L. A. Archer, Angew. Chem., Int. Ed., 2010, 49, 91589161.

46 B. G. Choi, M. Yang, S. C. Jung, K. G. Lee, J. G. Kim, H. Park, T. J. Park, S. B. Lee, Y. K. Han and Y. S. Huh, ACS Nano, 2013, 7, 2453-2460.

47 X. Duan, J. Ma, J. Lian and W. Zheng, CrystEngComm, 2014, 16, 2550-2559.

48 J. Olchowka, H. Hagemann, M. T. Delgado Pérez and C. Wickleder, Nanoscale, 2018, 10, 19706-19710.

49 L. R. Arana, J. Olchowka and H. Terraschke, Zeitschrift für Naturforschung B, 2019, 74, 147-152.

50 O. Zech, A. Stoppa, R. Buchner and W. Kunz, J. Chem. Eng. Data, 2010, 55, 1774-1778.

51 K. Hayamizu, Y. Aihara, H. Nakagawa, T. Nukuda and W. S. Price, J. Phys. Chem. B, 2004, 108, 19527-19532.

52 K. Ghandi, Green Sustainable Chem., 2014, 04, 44-53.

53 J. Wang, H. Wang, S. Zhang, H. Zhang and Y. Zhao, J. Phys. Chem. B, 2007, 111, 6181-6188.

54 S. Brunauer, P. H. Emmett and E. Teller, J. Am. Chem. Soc., 1938, 60, 309-319.

55 E. P. Barrett, L. G. Joyner and P. P. Halenda, J. Am. Chem. Soc., 1951, 73, 373-380. 
56 A. Kudielka, S. Bette, R. E. Dinnebier, M. Abeykoon, C. Pietzonka and B. Harbrecht, J. Mater. Chem. C, 2017, 5, 2899-2909.

57 X. Kang, X. Sun and B. Han, Adv. Mater., 2016, 28, 10111030.

$58 \mathrm{~K}$. Qi and W. Zheng, Current Opinion in Green and Sustainable Chemistry, 2017, 5, 17-23.

59 J. Lian, X. Duan, J. Ma, P. Peng, T. Kim and W. Zheng, ACS Nano, 2009, 3, 3749-3761.

60 W. Zheng, X. Liu, Z. Yan and L. Zhu, ACS Nano, 2009, 3, 115122.
61 Y. Zhou, J. H. Schattka and M. Antonietti, Nano Lett., 2004, 4, 477-481.

62 S. Cha, M. Ao, W. Sung, B. Moon, B. Ahlström, P. Johansson, Y. Ouchi and D. Kim, Phys. Chem. Chem. Phys., 2014, 16, 9591-9601.

63 H. Cui, F. Zhang, W. Ma, L. Wang and J. Xue, J. Sol-Gel Sci. Technol., 2016, 79, 83-88.

64 C. Zhong, Y. Deng, W. Hu, J. Qiao, L. Zhang and J. Zhang, Chem. Soc. Rev., 2015, 44, 7484-7539.

65 T. Brousse, D. Belanger and J. W. Long, J. Electrochem. Soc., 2015, 162, A5185-A5189. 